\title{
Research on Art Design Courses Score Evaluation Model
}

\author{
Ying Wang ${ }^{1}$ and Hongwei Xiao ${ }^{2}$ \\ ${ }^{1}$ Academy of Fine Arts, Northeast Normal University Changchun, Jilin Province, China \\ ${ }^{2}$ College of Automotive Engineering, Jilin University Changchun, Jilin Province, China \\ wangy986@nenu.edu.cn, xiaohw@jlu.edu.cn
}

\begin{abstract}
At present, specialty in comprehensive university in china, the art design is an important course in a practical. The score evaluation mainly through new model evaluation methods, evaluation forms and achievements to enrich the diversity evaluator scores organizational structure, so that the evaluation results more reasonable. Refinement score can reflect the learning process of students and their problems. This score can guiding students' independent learning effect. This can make the score assessment more objective, also can make the curriculum more closely with practice. After the actual examination and achieved good results, very helpful for teaching.

Index Terms - art design courses, score, the evaluation model
\end{abstract}

\section{Introduction}

Achievement is a record of the teaching process and learning outcomes reaction. Not only for student evaluation, the score is the evaluation of teachers. score can be used to analyze the effect of teaching, but also can judge curriculum programs, plans and implementation results. This process is an important part of teaching.

Art design courses score evaluation model is mainly for Chinese art design comprehensive university Students' evaluation of teaching activities.

\section{Art and Design Course Score Evaluation System's General Status}

At present, the existing score evaluation methods revealed many negative issues in many Chinese art design in comprehensive university, classroom teachers often caused worries on teaching situation. The score considerations are often based on subjective judgments of teachers and teacher emotional factors. Thus, the results of the evaluation lacks a quantitative criterion.

\section{A. Art Design Current Course Score Evaluation Criteria's Negative Effects}

Students get only one course score represented by score after courses learning. So that students can not clearly identify problems in their various knowledge learning, it is difficult to correctly interpret the idea about score results from teachers, score evaluation results are greatly reduced.Teachers come to different results of the score evaluation results often appear larger differences, but also to increase the difficulty of score evaluation.

\section{B. Art Design Course at Present score Evaluation Model is Relatively One-sided}

Currently, art and design course score evaluation criteria does not reflect the developmental characteristics of teaching activities, dynamic features of teaching activities and formation characteristics of teaching activities, ignoring the characteristics of Art Subjects teaching process.

score evaluation to the class within the overall level as a frame of reference for students. This is similar to norm-referenced way, which can be within a certain range level of students to be divided, to achieve the function of discovery and selection, Ignores individual student's progress and development, and can not achieve the score evaluation's function for the diagnosis and guidance.

\section{Art Design Course Score Evaluation is still lagging}

Score are released time lag, the evaluation results missed the best time feedback regulation, but also deprived the students of this study to improve and perfect opportunity.

\section{The Goal of New Model on The score Evaluation}

Multiple score evaluation content, score evaluation and diverse, focusing on the development of students and teachers, improving the quality, and effectively improve the score evaluation system. It is art and design course score evaluation of new models of macroeconomic goal.

To avoid using summative evaluation to assess achievement student's learning, the new model using formative assessment score to reflect students' learning process and the teaching process. Which reflect the students' learning progress and problems, thus contributing to the progress of students.

\section{The Content of Art Design Course Score Evaluation of New Models}

According to psychology and pedagogy theories, with reference to history and score at home and abroad horizontal comparison study evaluation system, score evaluation system specific contents are as follows:

\section{A. The Score Evaluation Methods Diversification}

Traditional single score of quantitative methods evaluation is the obvious limitations. Quality evaluation methods can give students a flexible, user-friendly space for development, this evaluation method is very demanding on the evaluators. And because of the subjectivity of evaluators, whose validity has been some impact. Therefore, in the current course score evaluation practice, we need to diversify student achievement evaluation from a cognitive perspective, the laws of art, innovative ability, the ability to tackle tough, arts management, creative execution, the work in terms of the implementation effects, etc. 


\section{B. The Evaluation Forms of Diversification}

The course objectives is often used as a basis for judging traditional score evaluation, it is paying attention to learning achievements, while ignoring the learning process, the score evaluation only conclusive evaluation.

Art design is not only a score evaluation score after learning, but should pay more attention to the learning process, as well as the motivation orientation and level of effort. Therefore, curriculum score evaluation forms must be diversified, namely diagnostic evaluation, formative assessment and summative assessment organic combination.

Only through the combination of these score evaluation methods, the score can be used accurately and fairly evaluate a student. This will not only ensure the score of the credibility and effectiveness of the evaluation results, but also to mobilize the enthusiasm of students and teachers.

\section{The Evaluation Forms of Score Evaluator}

In the traditional art design teaching score evaluation process, average score evaluators played by the teacher. This of course has its own advantages, but if limited to this, then it is biased. Because teachers' score evaluation can only represent the views of one teacher, but not entirely representative the people's opinions who directly or indirectly involved in the course.

Those Course participants and those affected by the programs' comments on an accurate evaluation of the results is indispensable.

The score evaluator diversification mainly refers to the activities of people involved in the evaluation in addition to teachers, but also including design agencies, full-time designers, consumer representatives, student groups and individuals as well as other relevant personnel within and outside the school.

Diversified score evaluation another point worth emphasizing is that the students on their own "work" can be a self-evaluation, which is not only give students a complaint on their own self-achievement, but also to provide students with a good opportunity to rethink.

\section{The Implementation Steps of Art Design Course score Evaluation New Models}

\section{A. Programs to Develop Score Evaluation System}

Through the research of many Countries' art design course score evaluation systems. Through major art institutions and national professional art and design Course Score evaluation system of surveys and studies.Teachers and related personnel based on previous theoretical studies to develop preliminary score evaluation system.This achievement evaluation system can be implemented in stages, and there was a clear intermediate targets and detailed implementation plan.

\section{B. Before the Implementation of Specific Programs Based Research}

Questionnaires for the teachers and the students before the class. Questionnaire covering the students' level of knowledge, professional skills, design skills, learning attitude. By understanding the students before class and after class professional level changes, the effects of the implementation of plans for the comparative study.

\section{The Clear Score Evaluation Criteria will be Told the Students}

Before class, according to the purpose of teaching to develop appropriate score evaluation standards and policies, and these are clearly informed students.

Students can clearly understand the score evaluation standards expected learning effect, which has guidelines to develop learning objectives and learning programs, students also become the subject of reform, increasing score evaluation system of participation.

\section{The Implementation of Score Evaluation Criteria}

The perpetrators of score evaluation criteria are the courses teachers. Under the guidance of teachers, student score evaluation criteria according to rules. Students can according the rules of score evaluation, initiative to acquire knowledge and application of knowledge, solving problem, creative design and completed other learning activities.

Curriculum evaluation based on student achievement in the curriculum learning process. Reflects the ability of the student score assessment as a basic framework. The student learning in the curriculum as reflected in the ability is based on the basic framework of the development of score evaluation system. Specific assessment score about the proportion of general skills or professional competence on the Table (1).

TABLE(1) Assessment score about the Proportion of General Skills or Professional Competence(\%)

\begin{tabular}{|c|c|c|c|c|c|c|}
\hline Score evaluators & Classroom teachers & Industry experts & Professionals & Virtual Consumers & Student self-assessment & Peer assessment \\
\hline Data compilation & 2 & & & & & \\
\hline Problem Analysis & 3 & & & & & \\
\hline Teamwork & 3 & & & & & \\
\hline Self-management & 2 & & & & & \\
\hline Sketching Structural & 3 & & & & & \\
\hline Design Professions & 10 & & & & & \\
\hline Creative execution & 5 & & & & & \\
\hline works produced & 5 & 5 & 3 & 1 & 1 & 1 \\
\hline Works show & 5 & 5 & 5 & 1 & 1 & 1 \\
\hline Creative elaboration & 2 & 2 & 2 & 1 & 1 & 1 \\
\hline Creativity & 10 & 5 & 5 & 2 & 2 & 2 \\
\hline The proportion of score & 50 & 20 & 15 & 5 & 5 & 5 \\
\hline
\end{tabular}


Each item in the score evaluation of the proportion is different. It can help students correct understanding of their own attitude. This makes students understand their own ability, knowledge and other aspects of the achievements or problems. The score evaluation model will score subdivided into 12 ratings units, each unit individually scored, the final score is derived by adding. score appraisal person extended to classroom teachers, industry experts, professionals, Virtual Consumers, students themselves, the other students, which can receive a more objective assessment of score, but also to make the curriculum and practice more closely.

Such score can improve learning methods to improve the quality of learning. Meanwhile, the score evaluation also help teachers understand the effectiveness and quality of courses. score provide feedback information to improve teaching, promote the course's perfect.

\section{E. After the Implementation of Score Evaluation Criteria on the Feedback}

The score evaluation results feedback is communication between teachers and students. Teachers to choose the best time and the best way to feedback student learning.

At every stage, the score evaluation results are timely informed the students. In the initial stages of learning courses, intermediate stage, 3/4 stage and the end of the stage, partial score was told students, so that students have the opportunity to perfect the next learning stage of the course.

Art design is an open subject, art design learning is no single answer. In other words, the student's learning result no right or wrong at all. Therefore, by all classroom teachers and some curriculum-related evaluation team composed of personnel, through communication and the results of the evaluation feedback to students. Meanwhile, the teachers through student freedom statements, questions and student answers, further analysis of student learning conditions.

Finally, Taking all factors, teachers get the final results of the evaluation, and feedback to students, and suggestions for improvement.

\section{Analysis}

By contrast, the students' ability levels than students' who did not participate in the experiment has improved greatly. It can be seen, the student mastery of the curriculum has improved greatly, the students' thinking and execution capabilities have been greatly improved .Understanding through visits, the students satisfaction with the course has definitely improved.

\section{Conclusion}

The implementation of score evaluation model had a positive influence. However, as the research project cycle was shorter, the number of samples was limited. Research process inevitably influencing factors, making the inevitable conclusions of this study had some limitations. Through the analysis of the study results, clarifies the current course grade evaluation system characteristics, the level of research. Study the existing problems and shortcomings will help improve the current Chinese Art design curriculum evaluation mechanism.

Research can become art design professional teaching evaluation system in advance guidance, but also for other courses score appraisal system reform to provide guidance.

\section{Acknowledgment}

Supported by Youth Foundation of Northeast Normal University Philosophy and Social Sciences School (Grant No. 11QN041).

\section{References}

[1] H.Zhang, "Reflect on Flux--Forecasting Art Education of National Taiwan University of Arts," Journal of Fujian Normal University (Philosophy and Social Science Edition), Jan 2008.

[2] Q.Liu, Q.Ni, "Study on the Teaching Method of Basic Design Course in Colleges and Universities--The Thinking Based on the Graphic Design Co urse Teaching," Art Panorama,2 2011.

[3] W.Lu. "Training Mode for Higher Art Design," Journal of Yibin Universi ty, 102009. 